\title{
Arterial Stiffness and Its Relationship to Cardiorespiratory Fitness in Children and Young Adults with a Fontan Circulation
}

\author{
Laurien C. M. Noortman ${ }^{1} \cdot$ Eero A. Haapala $^{2,3} \cdot$ Tim Takken $^{4,5}$ D
}

Received: 8 November 2018 / Accepted: 29 January 2019 / Published online: 15 February 2019

(c) The Author(s) 2019

\begin{abstract}
There are no previous studies on arterial stiffness and its associations with cardiorespiratory fitness in young Fontan patients. Therefore, we examined the arterial stiffness and its relationship to cardiorespiratory fitness in children and young adults with a Fontan circulation. Altogether, 17 Fontan patients and 26 healthy controls (16 females and 27 males aged 8-40 years) participated in this cross-sectional study. The cardiorespiratory fitness was assessed by cardiopulmonary exercise testing on a cycle ergometer and was defined as the standard deviation scores (SDS) of peak oxygen uptake per body mass $\left(\mathrm{VO}_{2 \text { peak }} / \mathrm{kg}\right)$ based on the national reference values and assessed with cardiopulmonary exercise testing on a cycle ergometer. Aortic pulse wave velocity $\left(\mathrm{PWV}_{\mathrm{ao}}\right)$ as a measure of arterial stiffness and aortic Augmentation Index (AIX) as a measure of peripheral arterial tone, were assessed by non-invasive oscillometric device from upper arm. Body adiposity was determined by body mass index SDS and the sport participation by interview. Data were analyzed using linear regression analyses and Pearson's correlations, adjusted for age and sex. Fontan patients had a lower $\mathrm{VO}_{2 \text { peak }} / \mathrm{kg}$-SDS ( -2.69 vs 0.078$)$, higher PWV $\mathrm{Po}_{\mathrm{ao}}-\mathrm{SDS}$ $(1.13$ vs -0.24$)$ and higher AIX $(19.26 \%$ vs $8.49 \%)$ in comparison with healthy controls. PWV $\mathrm{ao}_{\text {ao }}$ and AIX were negatively associated with $\mathrm{VO}_{2 \text { peak }} / \mathrm{kg}$ (standard regression coefficient $(\beta)-0.525,95 \%$ confidence interval $(\mathrm{CI})-0.722$ to -0.227 , $p<0.01$ and $\beta-0.371,95 \% \mathrm{CI}-0.672$ to $-0.080, p=0.014$ ). Young Fontan patients have the arterial stiffness of healthy people who are twice as old. Thereby, children and young adults with a Fontan circulation have a lower cardiorespiratory fitness and less sport participation. Arterial stiffness is inversely associated with cardiorespiratory fitness and exercise training might be an intervention to improve vascular health in this population.
\end{abstract}

Keywords Arterial stiffness · Cardiorespiratory fitness · Fontan circulation · Univentricular heart · Youth · Pulse wave velocity $\cdot$ Augmentation Index

\section{Introduction}

Tim Takken

T.takken@umcutrecht.nl

1 Faculty of Medicine, Utrecht University, Utrecht, The Netherlands

2 Faculty of Sport and Health Sciences, University of Jyväskylä, Jyvaskyla, Finland

3 Institute of Biomedicine, University of Eastern Finland, Kuopio, Finland

4 Child Development and Exercise Center, Wilhelmina Children's Hospital, P.O. Box 85090, 3508 AB Utrecht, The Netherlands

5 Partner of Shared Utrecht Pediatric Exercise Research (SUPER) Lab, Utrecht, The Netherlands
Approximately, 6-8 per 1000 children are born with a congenital heart disease (CHD) [1]. Fontan procedure is performed when there is congenitally one viable ventricle and a biventricular repair is not possible. Since the introduction of the Fontan procedure, most patients are able to survive into adulthood [2]. After this procedure, the blood from the superior and inferior vena cava is diverted to the pulmonary arteries, to partly repair the pulmonary blood flow [3]. Even when the Fontan procedure confers an improvement of ca. $20 \%$ in exercise tolerance, the patients still have a 30-40\% lower exercise tolerance than healthy people [3]. In particular, peak oxygen uptake $\left(\mathrm{VO}_{2 \text { peak }}\right)$ and peak heart rate $\left(\mathrm{HR}_{\text {peak }}\right)$ are impaired during physical activity [4]. Exercise is safe for stable Fontan patients and can be beneficial to increase exercise capacity [5]. Nevertheless, Fontan patients 
appear to be less engaged in physical exercise and this can have a negative impact on their vascular health [6].

The improvement in treatment of children with a CHD established that these patients can also reach the age at which the development of arteriosclerosis and its associated complications appear [2]. Arteriosclerosis is an important cause of the development of cardiovascular diseases and the process begins in early childhood [7]. Therefore, it is important to detect the development of arteriosclerosis at an early stage commence intervention and prevent cardiovascular morbidity and mortality.

The use of non-invasive measurements to determine the cardiovascular health of patients with a chronic disease has increased [8]. An impairment in the elasticity of the arterial walls is a sign of arteriosclerosis and a predictor of cardiovascular morbidity and mortality in the healthy population [9]. The aortic pulse wave velocity $\left(\mathrm{PWV}_{\mathrm{ao}}\right)$ can be used to measure the aortic stiffness and the $\mathrm{PWV}_{\mathrm{ao}}$ tends to increase with age [10]. The aorta Augmentation Index is a surrogate marker of peripheral arterial tone and decreases with the development of arteriosclerosis in healthy people [11]. When the peripheral resistance is high, the AIX will increase, because a larger proportion of the pulse wave will reflect from the peripheral arteries [12]. A study in adult Fontan patients has noted an increase in arterial stiffness of these patients using non-invasive measurements [8].

A recent study from our group showed that chronically ill or physically disabled children and adolescents with decreased cardiorespiratory fitness have a stiffer aorta [13]. This has been partly explained by an increase in waist circumference. Another study concludes that cardiorespiratory fitness is related to $\mathrm{PWV}_{\mathrm{ao}}$, but not to AIX in healthy adolescents [14].

Little research has been conducted into the arterial stiffness, cardiorespiratory fitness and vascular problems in young Fontan patients. Therefore, the aim of this study is to analyze the arterial stiffness and the relationship with cardiorespiratory fitness in children and young adults with a Fontan circulation. We will also analyze if the arterial stiffness will increase by age in the Fontan patients.

\section{Methods}

\section{Participants}

In this study, the data were collected between October 2016 and August 2018. Subjects were recruited as a part of a larger study investigating the effects of altitude on exercise capacity (HYPOXIA study). Tests were performed at rest and during exercise. The children and adolescents of the study were recruited in the Netherlands by a shared Utrecht Pediatric Exercise Research lab (Super-Lab Utrecht) [15].
The exercise tests were performed in the Wilhelmina Children's Hospital by an experienced exercise physiologist (Dr. T. Takken). 17 children and young adults with a Fontan circulation between the age of 8-40 were included. In addition, data from 26 healthy children and young adults between the age of 8-40 years were included. A subject was excluded from the study in case of an unstable cardiac function or fever. When the subject was not able to perform the exercise test on a cycle ergometer because of a mental or physical disability, he or she was also excluded from participation. Seven children or young adults were excluded, because the pulsations were not clear enough to measure the $\mathrm{PWV}_{\mathrm{ao}}$ and AIX.

\section{Ethical Approval}

The study was conducted in accordance with the Medical Research Involving Human Subjects Act (WMO) and Good Clinical Practice (GCP) and the principles of the Declaration of Helsinki. The participants of the study provided their informed consent before entering the study. When participants were under 18 years of age at the start of the study, their parents or caregivers had to sign the informed consent form. The medical ethics committee of the University Medical Centre Utrecht (Netherlands) approved the study.

\section{Assessment of Cardiorespiratory Fitness}

The peak oxygen uptake $\left(\mathrm{VO}_{2 \text { peak }}\right)$ as measure of cardiorespiratory fitness was assessed by Cardio Pulmonary Exercise Testing (CPET) on an electronically braked upright cycle ergometer (Lode Corival, Groningen, The Netherlands). A RAMP incremental Godfrey protocol was used during the CPET [16]. The participant breathed through a facemask (Hans Rudolph, Inc. USA) connected to a calibrated metabolic cart (Geratherm Respiratory $\mathrm{GmbH}$, Bad Kissingen, Germany). A gas analyzer and flow meter were used to measure oxygen $\left(\mathrm{VO}_{2}\right)$ and carbon dioxide volume $\left(\mathrm{VCO}_{2}\right)$ and breath-by-breath respiratory gas analyzes were performed during the test.

Children and young adults were verbally encouraged to perform the test until exhaustion. The exercise performance was at the maximum when there were subjective and objective signs of maximal effort (i.e. $\mathrm{RER}_{\text {peak }}\left(=\mathrm{VCO}_{2} /\right.$ $\left.\mathrm{VO}_{2}\right)>1.0$, heart rate $>180 / \mathrm{min}$, sweating, muscular fatigue, plateau of $\mathrm{VO}_{2}$ ).

The $\mathrm{VO}_{2 \text { peak }} / \mathrm{kg}(\mathrm{ml} / \mathrm{kg} / \mathrm{min})$ was used to measure the cardiorespiratory fitness. The standard deviations scores (SDS) of the $\mathrm{VO}_{2 \text { peak }}$ and the $\mathrm{VO}_{\text {2peak }} / \mathrm{kg}$ were calculated using the reference values of the healthy population in the Netherlands, adjusted for age and gender [17]. 


\section{Assessment of Body Size and Body Adiposity}

Patient body height was measured by stadiometer (Prof Lange, Germany) and the body weight was measured by standard scale (Seca, Hamburg, Germany). The body mass (kg) was divided by body height squared $\left(\mathrm{m}^{2}\right)$ to calculate the body mass index (BMI). The SDS's of the weight, height and BMI were calculated using the reference values of The Netherlands [18].

\section{Assessment of Sports Participation}

Amount of sport participation was accessed by interview and the children and adolescents were asked to determinate the amount of time a week they participate in sport. In this study, sport participation is defined as involvement in organized sports, but also daily exercise (i.e. biking to school, playing football with friends).

\section{Assessment of Arterial Stiffness}

Systolic and diastolic blood pressures were measured using an automated cuff (SunTech Tango M2, SunTech Medical, USA). For the assessment of arterial stiffness, this study used the aortic pulse wave velocity $\left(\mathrm{PWV}_{\mathrm{ao}}\right)$. The peripheral arterial tone is measured by the Augmentation Index (AIX). These measurements were assessed by an arteriograph (TensioMed, Budapest, Hungary), a non-invasive oscillometric tonometry device. The method described by TensioMed was used correctly [19]. Research shows a strong association between the $\mathrm{PWV}_{\text {ao }}$ and AIX measured with the arteriograph and invasively obtained measurements $(R>0.9)$ [19]. A measurement of the $\mathrm{PWV}_{\mathrm{ao}}$ with a SD greater than $1.0 \mathrm{~m} / \mathrm{s}$ was considered as a disturbance in the metering and the $\mathrm{PWV}_{\mathrm{ao}}$ was measured again. The SD to determinate the accuracy of the measuring was calculated by the algorithm of the software of TensioMed Arteriograph (Budapest, Hungary). The test was done at least twice a few minutes apart and the most accurate measurement was taken. When the participant could not be measured properly, the patient was excluded from the analysis. To define the SDS of the $\mathrm{PWV}_{\mathrm{ao}}$ the reference values provided by the manufacturer were taken (Tensiomed, Budapest, Hungary). The aortic length was determined by the length between the sternal notch and the symphysis. The $\mathrm{PWV}_{\mathrm{ao}}$ and AIX were calculated using the following equations [19]:

$\mathrm{PWV}_{\mathrm{ao}}=$ aortic length $/($ reflection time $/ 2)(\mathrm{m} / \mathrm{s})$

AIX $=(($ amplitude of the reflection wave -amplitude of the direct wave)/pulse pressure) $\times 100(\%)$.

\section{Statistical Methods}

The independent-Samples $T$ test was used to compare the baseline characteristics between boys and girls or controls and Fontan patients. No significant correlations were found between gender and the baseline characteristics, so the analysis of the data of the different genders were combined. Thereby, the baseline characteristics of the different groups (Fontan or control) were controlled to be corresponding. The baseline characteristics are presented as mean \pm standard deviation or percentage.

The associations between the cardiorespiratory fitness, BMI, sport participation and $\mathrm{PWV}_{\mathrm{ao}}$ or AIX were assessed using Pearson's correlation. The correlation between $\mathrm{PWV}_{\mathrm{ao}}$ or AIX and age were analyzed using linear regression analyzes. To correct for the age and gender, the SDS of the BMI, $\mathrm{PWV}_{\mathrm{ao}}, \mathrm{VO}_{2 \text { peak }}$ and $\mathrm{VO}_{2 \text { peak }} / \mathrm{kg}$ were taken. The associations with the AIX or $\mathrm{PWV}_{\mathrm{ao}}$ were controlled for systolic blood pressure.

Data were analyzed using the SPSS Statics, Version 25.0 (International Business Machines Corporation, Armonk, New York, United states of America). All tests were twotailed, and values were considered statistically significant when the $p$ value $<0.05$.

\section{Results}

\section{Baseline Characteristics}

A total of 43 children and young adults comprised the study cohort; 17 Fontan patients and 26 healthy controls. There was no significant difference between the baseline data of the included and excluded group $(p>0.05)$. The gender distribution and average age between the Fontan patients and control were comparable, however, the BMI was lower for the Fontan patients (Table 1).

\section{Fitness and arterial stiffness}

In comparison to the control group, the Fontan patients have a significant lower $\mathrm{VO}_{2 \text { peak }} / \mathrm{kg}(p=0.0001)$, higher $\mathrm{PWV}_{\mathrm{ao}}$ $(p=0.003)$ and higher AIX values $(p=0.0001)$ (Table 2$)$.

In the Fontan patients, no significant correlation was found between age and AIX $(\beta 0.235,95 \% \mathrm{CI}-0.250$ to $0.616 p=0.364)$. However, the $\mathrm{PWV}_{\mathrm{ao}}$ deviation of the Fontan patients tended to become larger with age (Fig. 1), but this correlation was not statistically significant $(\beta 0.301,95 \%$ CI -0.088 to $0.644, p=0.240)$. In the control group there was no correlation between $\mathrm{AIX}$ or $\mathrm{PWV}_{\mathrm{ao}}$ with age. 
Table 1 Baseline characteristics

\begin{tabular}{|c|c|c|c|c|c|c|c|}
\hline & \multirow[t]{2}{*}{ All } & \multicolumn{3}{|l|}{ Gender } & \multicolumn{3}{|l|}{ Control or Fontan } \\
\hline & & Boys $(n=27)$ & Girls $(n=16)$ & $p$ value & Control $(n=26)$ & Fontan $(n=17)$ & $p$ value \\
\hline Age (years) & $21.0 \pm 9.0$ & $21.7 \pm 9.7$ & $19.8 \pm 7.9$ & 0.514 & $22.23 \pm 9.0$ & $19.12 \pm 9.1$ & 0.274 \\
\hline Fontan circulation (\%) & 39.5 & 40.7 & 37.5 & & - & - & \\
\hline Boys (\%) & 62.8 & - & - & & 61.5 & 64.7 & \\
\hline Sport participation (hours/week) & $5.9 \pm 3.2$ & $6.1 \pm 3.2$ & $5.6 \pm 3.1$ & 0.660 & $6.9 \pm 3.2$ & $4.5 \pm 2.6$ & 0.016 \\
\hline Body height $(\mathrm{cm})$ & $168.5 \pm 15.6$ & $171.2 \pm 15.8$ & $163.9 \pm 14.1$ & 0.135 & $174.1 \pm 13.3$ & $159.9 \pm 15.2$ & 0.002 \\
\hline Body weight (kg) & $59.2 \pm 18.3$ & $60.8 \pm 19.1$ & $56.5 \pm 16.9$ & 0.464 & $65.4 \pm 17.2$ & $49.7 \pm 16$ & 0.004 \\
\hline Body mass index $\left(\mathrm{kg} / \mathrm{m}^{2}\right)$ & $20.3 \pm 3.6$ & $20.1 \pm 3.5$ & $20.7 \pm 3.8$ & 0.640 & $21.3 \pm 3.4$ & $18.96 \pm 3.4$ & 0.038 \\
\hline Body mass index SDS & $0.11 \pm 1.11$ & $0.06 \pm 1.13$ & $0.19 \pm 1.11$ & 0.726 & $0.41 \pm 0.93$ & $-0.33 \pm 1.23$ & 0.033 \\
\hline Systolic blood pressure in rest $(\mathrm{mmHg})$ & $132.5 \pm 13.4$ & $135.7 \pm 13.0$ & $127.1 \pm 12.6$ & 0.039 & $133.3 \pm 10.9$ & $131.2 \pm 16.8$ & 0.622 \\
\hline Diastolic blood pressure in rest $(\mathrm{mmHg})$ & $73.1 \pm 10.2$ & $74.5 \pm 10.4$ & $70.7 \pm 9.7$ & 0.242 & $72.6 \pm 9.6$ & $73.77 \pm 11.4$ & 0.728 \\
\hline
\end{tabular}

The data are mean \pm SD or percentages and the $p$ values from the $t$ test

Table 2 Fitness and arterial stiffness characteristics of the subjects

\begin{tabular}{|c|c|c|c|c|c|c|c|}
\hline & \multirow[t]{2}{*}{ All } & \multicolumn{3}{|l|}{ Gender } & \multicolumn{3}{|l|}{ Control or Fontan } \\
\hline & & Boys $(n=27)$ & Girls $(n=16)$ & $p$ value & Control $(n=26)$ & Fontan $(n=17)$ & $p$ value \\
\hline $\mathrm{VO}_{2 \text { peak }}(\mathrm{L} / \mathrm{min})$ & $2.3 \pm 1.1$ & $2.6 \pm 1.3$ & $2.0 \pm 0.7$ & 0.102 & $2.95 \pm 1.03$ & $1.40 \pm 0.45$ & $<0.001$ \\
\hline $\mathrm{VO}_{2 \text { peak }} \mathrm{SDS}$ & $-1.63 \pm 2.49$ & $-1.72 \pm 2.46$ & $-1.49 \pm 2.60$ & 0.767 & $-0.39 \pm 2.25$ & $-3.53 \pm 1.40$ & $<0.001$ \\
\hline $\mathrm{VO}_{2 \text { peak }} / \mathrm{kg}(\mathrm{ml} / \mathrm{kg} / \mathrm{min})$ & $38.6 \pm 11.3$ & $40.8 \pm 11.6$ & $34.9 \pm 10.0$ & 0.100 & $44.6 \pm 8.8$ & $29.4 \pm 8.2$ & $<0.001$ \\
\hline $\mathrm{VO}_{2 \text { peak }} / \mathrm{kg}(\mathrm{ml} / \mathrm{kg} / \mathrm{min}) \mathrm{SDS}$ & $-1.02 \pm 1.97$ & $-1.18 \pm 2.05$ & $-0.73 \pm 1.85$ & 0.473 & $0.078 \pm 1.46$ & $-2.69 \pm 1.38$ & $<0.001$ \\
\hline $\mathrm{PWV}_{\text {ao }}(\mathrm{m} / \mathrm{s})$ & $6.9 \pm 1.36$ & $7.0 \pm 1.3$ & $6.7 \pm 1.4$ & 0.623 & $6.4 \pm 0.92$ & $7.6 \pm 1.61$ & 0.003 \\
\hline $\mathrm{PWV}_{\mathrm{ao}} \mathrm{SDS}$ & $0.30 \pm 1.05$ & $0.35 \pm 1.06$ & $0.22 \pm 1.07$ & 0.713 & $-0.24 \pm 0.68$ & $1.13 \pm 0.98$ & $<0.001$ \\
\hline $\operatorname{AIX}(\%)$ & $12.8 \pm 9.0$ & $11.5 \pm 10.2$ & $14.9 \pm 6.3$ & 0.223 & $8.49 \pm 6.10$ & $19.26 \pm 8.93$ & $<0.001$ \\
\hline
\end{tabular}

$S D S$ standard deviation score, $P W V_{a o}$ aortic pulse wave velocity, $A I X$ aortic augmentation index $(\%), V O_{2 p e a k}$ peak oxygen uptake

The data are mean \pm SD or percentages and the $p$ values from the $t$ test

Fig. 1 Relationship between arterial stiffness and age in Fontan patients. $P W V_{a o}$ aortic pulse wave velocity, AIX Aortic Augmentation Index (\%). $\mathrm{PWV}_{\text {ao }}$ is the standard deviation score compared to normal values for age and gender. The linear regression lines are showed for the subgroup of Fontan patients and the controls

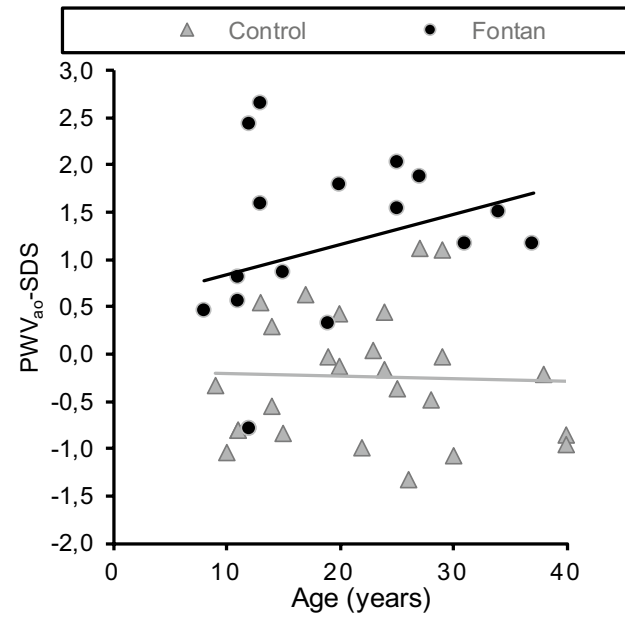

\section{Associations of Cardiorespiratory Fitness with Arterial Stiffness}

A higher $\mathrm{VO}_{2 \text { peak }} / \mathrm{kg}$ was significantly associated with a lower $\mathrm{PWV}_{\mathrm{ao}}$ after normalizing for age and gender (Fig. 2).
No significant relationship was found between the hours of sport participation or BMI and the $\mathrm{PWV}_{\text {ao }}$ (Table 3).

No significant association was found between age or gender and the AIX (respectively $p=0.678$ and $p=0.223$ ). After normalizing for age and gender, $\mathrm{VO}_{2 \text { peak }} / \mathrm{kg}$ and $\mathrm{BMI}$ 
were negatively associated with AIX (Table 4). A higher amount of sport participation was associated with a lower AIX.

In the sub-analyzes of the Fontan group, no significant associations were found between $\mathrm{VO}_{2 \text { peak }} / \mathrm{kg}$ per body mass, BMI or sport participation and the AIX nor with the $\mathrm{PWV}_{\mathrm{ao}}$ (Tables 3, 4).

\section{Discussion}

In our study, children and young adults with a Fontan circulation had a higher $\mathrm{PWV}_{\mathrm{ao}}$ and AIX than the controls, indicating that the Fontan patients have stiffer arteries than healthy controls (Fig. 1). The mean $\mathrm{PWV}_{\mathrm{ao}}$ of the patients with a Fontan circulation was $7.6 \mathrm{~m} / \mathrm{s}$ and this correlates to
Fig. 2 Correlation between arterial stiffness and cardiorespiratory fitness divided in subgroup of control and Fontan. $P W V_{a o}$ aortic pulse wave velocity, $A I X$ Aortic Augmentation Index (\%), $\mathrm{VO}_{2 \text { peak }} / \mathrm{kg}$ peak oxygen uptake per body mass. $\mathrm{VO}_{2 \text { peak }} / \mathrm{kg}$ and $\mathrm{PWV}_{\mathrm{ao}}$ are the standard deviations scores. The linear regression line is showed for the two groups (Fontan and controls) combined

Table 3 Associations between aortic peak wave velocity and cardiorespiratory fitness, BMI and sport participation
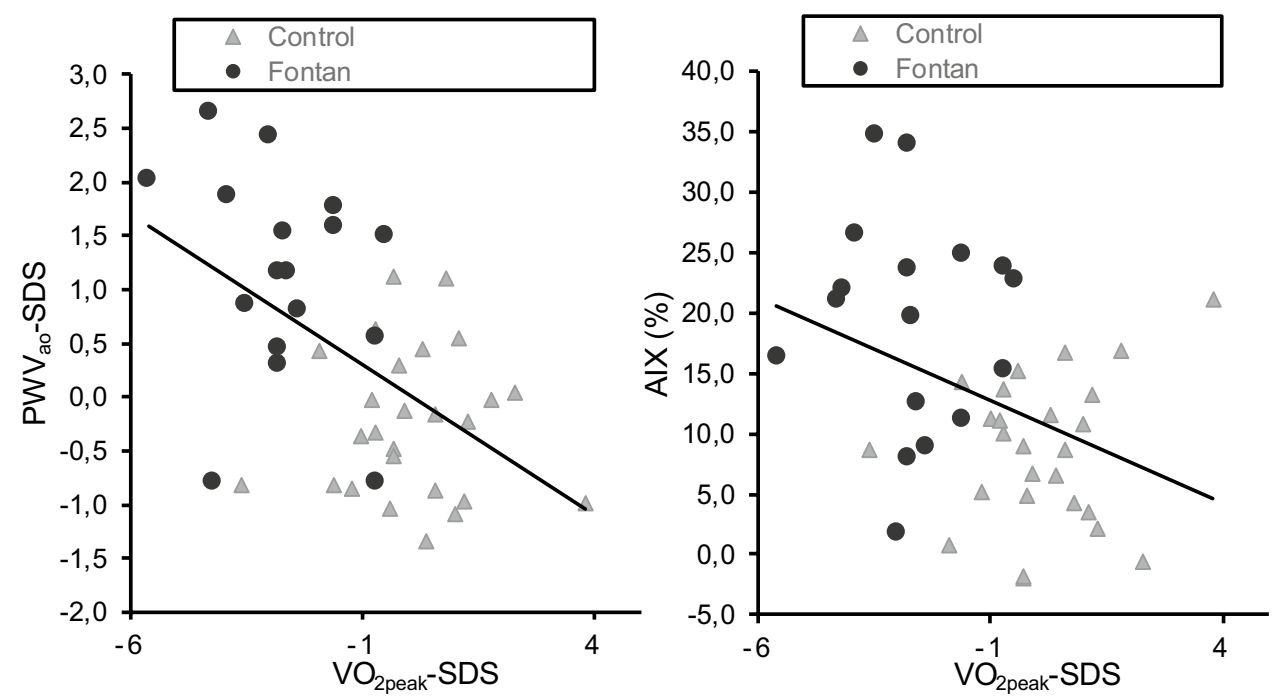

\begin{tabular}{|c|c|c|c|c|c|c|}
\hline & \multicolumn{6}{|l|}{$\mathrm{PWV}_{\mathrm{ao}}$} \\
\hline & \multicolumn{3}{|c|}{ Combined $(n=43)$} & \multicolumn{3}{|c|}{ Fontan $(n=17)$} \\
\hline & $B$ & $95 \% \mathrm{CI}$ & $p$ value & $B$ & $95 \% \mathrm{CI}$ & $p$ value \\
\hline $\mathrm{VO}_{2 \text { peak }} / \mathrm{kg}$ & -0.525 & -0.722 to -0.227 & $<0.001$ & -0.279 & -0.698 to 0.362 & 0.278 \\
\hline BMI & -0.150 & -0.491 to 0.232 & 0.343 & 0.110 & -0.398 to 0.490 & 0.673 \\
\hline Sport participation & -0.211 & -0.466 to 0.090 & 0.186 & -0.084 & -0.586 to 0.396 & 0.748 \\
\hline
\end{tabular}

The regression coefficients $(B)$ and their $95 \%$ confidence intervals $(\mathrm{CI})$ are showed for the standard deviations scores of $\mathrm{VO}_{2 \text { peak }} / \mathrm{kg}, \mathrm{PWV}_{\mathrm{ao}}$ and $\mathrm{BMI}$, adjusted for age and gender. The sport participation is in hours/week. The results are showed for all the participants (Fontan and control group combined) and for just the Fontan group

$V O_{2 p e a k} / \mathrm{kg}$ peak oxygen uptake per body mass, $P W V_{a o}$ aortic pulse wave velocity, $B M I$ body mass index

Table 4 Associations between aortic augmentation index (AIX), cardiorespiratory fitness, BMI and sport participation

\begin{tabular}{|c|c|c|c|c|c|c|}
\hline & \multicolumn{6}{|l|}{ AIX } \\
\hline & \multicolumn{3}{|c|}{ Combined $(n=43)$} & \multicolumn{3}{|c|}{ Fontan $(n=17)$} \\
\hline & $B$ & $95 \% \mathrm{CI}$ & $p$ value & $B$ & $95 \% \mathrm{CI}$ & $p$ value \\
\hline $\mathrm{VO}_{2 \text { peak }} / \mathrm{kg}$ & -0.371 & -0.672 to -0.080 & 0.014 & -0.065 & -0.411 to 0.230 & 0.804 \\
\hline BMI & -0.438 & -0.668 to -0.133 & 0.004 & -0.366 & -0.705 to 0.071 & 0.149 \\
\hline Sport participation & -0.319 & -0.562 to -0.029 & 0.042 & -0.184 & -0.607 to 0.222 & 0.479 \\
\hline
\end{tabular}

The regression coefficients $(B)$ and their $95 \%$ confidence intervals $(\mathrm{CI})$ are showed for the standard deviations scores of $\mathrm{VO}_{2 \text { peak }} / \mathrm{kg}$ and BMI, adjusted for age and gender. The sport participation is in hours/week. The results are showed for all the participants (Fontan and control group combined) and for just the Fontan group

$V O_{2 p e a k} / \mathrm{kg}$ peak oxygen uptake per body mass, $A I X$ Aortic Augmentation Index (\%), BMI body mass index 
a vascular age of 38-39 years, while the mean age of the patients was only 19 years. This finding indicates that Fontan patients must deal with the risk of cardiovascular diseases at a much younger age [7]. Other studies in patients children and adolescents with a Fontan circulation also conclude that Fontan patients have stiffer arteries [20-22].

Thereby, our results show that the deviation from the normal values becomes somewhat greater with age in the group of Fontan patients. This suggests not only that Fontan patients have the arterial stiffness of older arteries but also that the increase in stiffness during aging is more existent than in the control group. However, the correlation between age and a higher PWV $_{a o}$ deviation and AIX as not significant, probably because of the low sample size. Nonetheless, other studies also found that young Fontan patients have a less deviant stiffness than older Fontan patients, which may suggest that the abnormalities arise with age [23, 24].

There might be a few reasons why Fontan patients have stiffer arteries. First of all, specific gene mutations are known that are involved in the heart malformation by CHD and some of these genes are important in the angiogenesis $[20,21]$. Mutations in those genes might cause malformation of the arteries. Besides, patients with a Fontan circulation have a higher endothelin-1 level compared to healthy people [8]. Endothelin-1 has an important function in the pathophysiology of organ-injury after a cardiopulmonary bypass, by inducing proliferation, inflammation and vasoconstriction and might increase arterial stiffness [22, 24, 25]. Thereby, Fontan patients have a decreased concentration of nitric oxide, which causes reduction in flow-mediated dilatation of the arteries and the effect is greater after a longer cyanotic time before the procedure [26, 27]. Finally, the blood flow in the lungs and systemic circulation is impaired in Fontan patients [28], which changes shear stress and dyshomeostasis of the arteries [29]. The cardiac output is lower, and the arterial tonus increases by sympathetic activity to maintain a normal blood pressure, causing stiffer arteries [30].

The sample size of this study is too small to make a subgroup analyses for the Fontan patients to determine the relation between arterial stiffness and cardiorespiratory fitness. However, our results show a negative relationship between $\mathrm{PWV}_{\mathrm{ao}}$ and cardiorespiratory fitness when the subgroups were combined. We observed no relationship with sport participation nor with BMI to $\mathrm{PWV}_{\mathrm{ac}}$. The associations between a higher cardiorespiratory fitness or higher sport participation and a lower AIX were found. Few studies that used CPET to measure cardiorespiratory fitness and related $\mathrm{VO}_{2 \text { peak }}$ to arterial stiffness. However, the inverse correlation between the arterial stiffness and the cardiorespiratory fitness are in line with studies in a population of healthy children and young adults [31,32]. A study in young patients with a chronic disease or physical disabilities that used various exercise tests, suggests an association between the arterial stiffness and cardiorespiratory fitness, but they found waist circumference to be confounding [13]. In the present study, the waist circumference was not measured unfortunately. Other studies with a healthy population of children and young adults show a significant negative correlation between the cardiorespiratory fitness and the $\mathrm{PWV}_{\mathrm{ao}}$, but this negative correlation was not found with AIX [14, 33, 34]. Meanwhile, another study in men without coronary heart diseases and a study in adults with a Fontan circulation show an association between AIX and cardiorespiratory fitness [8, 35]. A higher AIX in children is not always pathological, because growth and maturation might increase the AIX [36]. The AIX might be a good index of wave reflection caused by the peripheral arterial tone and the AIX tends to be more sensitive for natural fluctuation than the $\mathrm{PWV}_{\text {ao }}$ [37].

The impaired dilatation caused by arterial stiffening leads to exercise limitation, because the skeletal muscles receive less oxygen [38]. Thereby, studies show that a sedentary lifestyle is associated with endothelial dysfunction and arteriosclerosis [39]. Especially when the Fontan patients already have the arterial stiffness of someone who is twice their age, physical activity is important. Exercise and thereby an increase in shear stress, contribute to a better endothelial function and might help in reendothelialization [40]. Thus, it can be beneficial for the Fontan patients to be helped by creating a healthy and active lifestyle to improve endothelial function and the cardiorespiratory fitness [41]. The results can also be used for the development of therapeutic interventions to improve the arterial stiffness in Fontan patients.

The present study used a reliable and consistent method for assessing the PWV $\mathrm{Po}_{\mathrm{a}}$, AIX and cardiorespiratory fitness [19]. In addition, many other studies were compared with the present study to confirm the findings.

\section{Limitations}

This cross-sectional study has some inherent limitations. The sample size of the study was too small to do reliable subgoup analyzes. Additional research with a bigger sample size is needed to draw robust conclusions for patients with a Fontan circulation. Furthermore, this study did not adjust for waist circumference, body fat percentage and fat-free mass, because some of the Fontan patients have a pacemaker and the body composition could not be measured by the bioelectrical impedance analysis. Other studies showed that those values might be associated with $\mathrm{PWV}_{\mathrm{ao}}$ and AIX [13, 14]. The sport participation was assessed by asking how many hours a week the participant of the study used for sport, but no distinction was made between high and low intensity and daily physical activity (e.g. biking to school) was also included in this estimate. The AIX was not normalized for age and gender, however there were no significant 
correlations found in the data of our study between the AIX and age or gender.

We also recommend performing a follow-up study to monitor the longitudinal changes in vascular aging of patients with a Fontan circulation. To confirm our findings, the present study should be performed in a larger, multicenter population. In addition, longitudinal research could be done about the effect of a personalized sport program for children with a Fontan circulation on the arterial stiffness and cardiorespiratory fitness [41]. Finally, research must be conducted into whether vasodilators can be beneficial for the Fontan patients [42]. However, we consider the results of our study of clinical importance because of the large increase in vascular age.

\section{Conclusion}

Children and young adults with a Fontan circulation have the arterial stiffness of healthy people who are twice as old. Thereby, young patients with Fontan circulation have a lower cardiorespiratory fitness and lower sport participation. A higher arterial stiffness is associated with a lower cardiorespiratory fitness. Exercise training to improve the cardiorespiratory fitness might be an intervention to improve vascular health in children and young adults with a Fontan circulation. Further research is needed to confirm these assumptions in Fontan patients.

Acknowledgements The authors of this study want to show their gratitude to the children and young adults who participated in the HYPOXIA-study.

\section{Compliance with Ethical Standards}

Conflict of interest The authors of this study declare that there are no conflicts of interest.

Ethical Approval All procedures performed in studies involving human participants were in accordance with the ethical standards of the institutional and/or national research committee and with the 1964 Helsinki declaration and its later amendments or comparable ethical standards.

Informed Consent All the included participants of the study gave informed consent. When participants were under 18 years of age, their parents or caregivers gave informed consent.

Open Access This article is distributed under the terms of the Creative Commons Attribution 4.0 International License (http://creativeco mmons.org/licenses/by/4.0/), which permits unrestricted use, distribution, and reproduction in any medium, provided you give appropriate credit to the original author(s) and the source, provide a link to the Creative Commons license, and indicate if changes were made.

\section{References}

1. Hoffman JIE, Kaplan S (2002) The incidence of congenital heart disease. J Am Coll Cardiol 39:1890-1900

2. McManus B (2010) Adult congenital heart disease-challenges and opportunities for pathologists. Cardiovasc Pathol 19:281-285

3. Brassard P, Bédard E, Jobin J, Rodés-Cabau J, Poirier P (2006) Exercise capacity and impact of exercise training in patients after a Fontan procedure: a review. Can J Cardiol 22:489-495

4. Ohuchi H, Negishi J, Noritake K, Hayama Y, Sakaguchi H, Miyazaki A, Kagisaki K, Yamada O (2015) Prognostic value of exercise variables in 335 patients after the fontan operation: a 23-year single-center experience of cardiopulmonary exercise testing. Congenit Heart Dis 10:105-116

5. Takken T, Hulzebos HJ, Blank a C, Tacken MHP, Helders PJM, Strengers JLM (2007) Exercise prescription for patients with a Fontan circulation: current evidence and future directions. Neth Heart J 15:142-147

6. Hedlund ER, Lundell B, Villard L, Sjï ¿1/2berg G (2016) Reduced physical exercise and health-related quality of life after Fontan palliation. Acta Paediatr Int J Paediatr 105:1322-1328

7. Kones R (2011) Primary prevention of coronary heart disease: integration of new data, evolving views, revised goals, and role of rosuvastatin in management. A comprehensive survey. Drug Des Devel Ther 5:325-380

8. Tomkiewicz-Pajak L, Dziedzic-Oleksy H, Pajak J, Olszowska M, Kolcz J, Komar M, Podolec P (2014) Arterial stiffness in adult patients after Fontan procedure. Cardiovasc Ultrasound. https:// doi.org/10.1186/1476-7120-12-15

9. Cecelja M, Chowienczyk P (2012) Role of arterial stiffness in cardiovascular disease. JRSM Cardiovasc Dis doi. https://doi. org/10.1258/cvd.2012.012016

10. Hidvégi EV, Illyés M, Benczúr B, Böcskei RM, Rátgéber L, Lenkey Z, Molnár FT, Cziráki A (2012) Reference values of aortic pulse wave velocity in a large healthy population aged between 3 and 18 years. J Hypertens 30:2314-2321

11. Rosenbaum D, Giral P, Chapman J, Rached FH, Kahn JF, Bruckert E, Girerd X (2013) Radial augmentation index is a surrogate marker of atherosclerotic burden in a primary prevention cohort. Atherosclerosis 231:436-441

12. Wilhelm B, Klein J, Friedrich C, Forst S, Pfützner A, Kann PH, Weber MM, Forst T (2007) Increased arterial augmentation and augmentation index as surrogate parameters for arteriosclerosis in subjects with diabetes mellitus and nondiabetic subjects with cardiovascular disease. J Diabetes Sci Technol 1:260-263

13. Haapala EA, Lankhorst K, De Groot J, Zwinkels M, Verschuren O, Wittink H, Backx FJG, Visser-Meily A, Takken T (2017) The associations of cardiorespiratory fitness, adiposity and sports participation with arterial stiffness in youth with chronic diseases or physical disabilities. Eur J Prev Cardiol. https://doi. org/10.1177/2047487317702792

14. Haapala EA, Laukkanen JA, Takken T, Kujala UM, Finni T (2018) Peak oxygen uptake, ventilatory threshold, and arterial stiffness in adolescents. Eur J Appl Physiol. https://doi.org/10.1007/s0042 1-018-3963-3

15. Utrecht S-L (2018) Utrecht Pediatric Exercise Research-Lab. http://www.super-lab.nl/hypoxia-voorlopige-resultaten/. Accessed 7 Sept 2018

16. Godfrey S, Davies CT, Wozniak E, Barnes CA (1971) Cardiorespiratory response to exercise in normal children. Clin Sci 40:419-431

17. Bongers BC, Hulzebos EHJ, van Brussel M, Takken T (2014) Pediatric norms for cardiopulmonary exercise testing: in relation to gender and age. Uitgeverij BOXPress, 's-Hertogenbosch 
18. Schönbeck Y, Talma H, von Dommelen P, Bakker B, Buitendijk SE, Hirasing RA, van Buuren S (2011) Increase in prevalence of overweight in dutch children and adolescents: a comparison of nationwide growth studies in 1980, 1997 and 2009. PLoS ONE 6:e27608

19. Horváth IG, Németh Á, Lenkey Z, Alessandri N, Tufano F, Kis P, Gaszner B, Cziráki A (2010) Invasive validation of a new oscillometric device (Arteriograph) for measuring augmentation index, central blood pressure and aortic pulse wave velocity. J Hypertens 28:2068-2075

20. Rhee S, Chung JI, King DA et al (2018) Endothelial deletion of Ino80 disrupts coronary angiogenesis and causes congenital heart disease. Nat Commun. https://doi.org/10.1038/s41467-017-02796 $-3$

21. Glidewell SC, Miyamoto SD, Grossfeld PD, Clouthier DE, Coldren CD, Stearman RS, Geraci MW (2015) Transcriptional impact of rare and private copy number variants in hypoplastic left heart syndrome. Clin Transl Sci 8:682-689

22. Beghetti M, Black SM, Fineman JR (2005) Endothelin-1 in congenital heart disease. Pediatr Res 57:16R-20R

23. Myers K, Leung MT, Terri Potts M, Potts JE, Sandor GGS (2013) Noninvasive assessment of vascular function and hydraulic power and efficiency in pediatric Fontan patients. J Am Soc Echocardiogr 26:1221-1227

24. Natarajan S, Heiss C, Yeghiazarians Y, Fineman JR, Teitel DF, Tacy TA (2009) Peripheral arterial function in infants and young children with one-ventricle physiology and hypoxemia. Am J Cardiol 103:862-866

25. Bhat DP, Gupta P, Aggarwal S (2015) Elevated aortic augmentation index in children following Fontan palliation: evidence of stiffer arteries? Pediatr Cardiol 36:1232-1238

26. Jin SM, Noh C Il, Bae EJ, Choi JY, Yun YS (2007) Impaired vascular function in patients with Fontan circulation. Int J Cardiol 120:221-226

27. Mahle WT, Todd K, Fyfe DA (2003) Endothelial function following the Fontan operation. Am J Cardiol 91:1286-1288

28. Moyle KR, Mallinson GD, Occleshaw CJ, Cowan BR, Gentles TL (2006) Wall shear stress is the primary mechanism of energy loss in the Fontan connection. Pediatr Cardiol 27:309-315

29. Chiu J-J, Chien S (2011) Effects of dsisturbed flow on vascular endothelium: pathophysiological basis and clinical perspectives. Physiol Rev 91:327-387

30. Lambert E, D'Udekem Y, Cheung M et al (2013) Sympathetic and vascular dysfunction in adult patients with Fontan circulation. Int J Cardiol 167:1333-1338

31. Sakuragi S, Abhayaratna K, Gravenmaker KJ, O'reilly C, Sri Kusalanukul W, Budge MM, Telford RD, Abhayaratna WP (2009) Influence of adiposity and physical activity on arterial stiffness in healthy children the lifestyle of our kids study. Hypertension 53:611-616

32. Pahkala K, Laitinen TT, Heinonen OJ, Viikari JSA, Ronnemaa T, Niinikoski H, Helajarvi H, Juonala M, Simell O, Raitakari OT
(2013) Association of fitness with vascular intima-media thickness and elasticity in adolescence. Pediatrics 132:e77-e84

33. Stöhr EJ, McDonnell B, Thompson J, Stone K, Bull T, Houston R, Cockcroft J, Shave R (2012) Left ventricular mechanics in humans with high aerobic fitness: adaptation independent of structural remodelling, arterial haemodynamics and heart rate. J Physiol 590:2107-2119

34. Veijalainen A, Tompuri T, Haapala EA, Viitasalo A, Lintu N, Väistö J, Laitinen T, Lindi V, Lakka TA (2016) Associations of cardiorespiratory fitness, physical activity, and adiposity with arterial stiffness in children. Scand J Med Sci Sport 26:943-950

35. Binder J, Bailey KR, Seward JB, Squires RW, Kunihiro T, Hensrud DD, Kullo IJ (2006) Aortic augmentation index is inversely associated with cardiorespiratory fitness in men without known coronary heart disease. Am J Hypertens 19:1019-1024

36. McEniery CM, Yasmin, Hall IR, Qasem A, Wilkinson IB, Cockcroft JR (2005) Normal vascular aging: differential effects on wave reflection and aortic pulse wave velocity-the Anglo-Cardiff Collaborative Trial (ACCT). J Am Coll Cardiol. https://doi. org/10.1016/j.jacc.2005.07.037

37. Haapala EA, Veijalainen A, Kujala UM, Finni T (2018) Reproducibility of pulse wave velocity and augmentation index derived from non-invasive occlusive oscillometric tonometry analysis in adolescents. Clin Physiol Funct Imaging. https://doi.org/10.1111/ cpf. 12528

38. Inai K, Saita Y, Takeda S, Nakazawa M, Kimura H (2004) Skeletal muscle hemodynamics and endothelial function in patients after Fontan operation. Am J Cardiol 93:792-797

39. Laufs U, Wassmann S, Czech T, Münzel T, Eisenhauer M, Böhm M, Nickenig G (2005) Physical inactivity increases oxidative stress, endothelial dysfunction, and atherosclerosis. Arterioscler Thromb Vasc Biol. https://doi.org/10.1161/01.ATV.0000158311 .24443.af

40. Xia WH, Yang Z, Xu SY, Chen L, Zhang XY, Li J, Liu X, Qiu YX, Shuai XT, Tao J (2012) Age-related decline in reendothelialization capacity of human endothelial progenitor cells is restored by shear stress. Hypertension 59:1225-1231

41. Tacken M, van der Bom J, Takken T (2006) Conditietraining bij een kind met een univentriculair hart (Fontan-circulatie). In: Fysioth. Casuïstiek - Boekblok. Bohn Stafleu van Loghum, Houten, pp 1-7. https://doi.org/10.1007/978-90-313-8645-1_1

42. Snarr BS, Paridon SM, Rychik J, Goldberg DJ (2015) Pulmonary vasodilator therapy in the failing Fontan circulation: rationale and efficacy. Cardiol Young 25:1489-1492

Publisher's Note Springer Nature remains neutral with regard to jurisdictional claims in published maps and institutional affiliations. 